\title{
An incidental giant preperitoneal fibrolipoma diagnosed during laparoscopic cholecystectomy
}

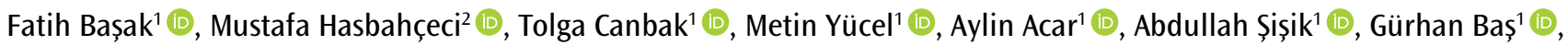
Murat Hakan Karabulut ${ }^{3}$ (i), Gözde Kır ${ }^{3}$ (D)

\section{ABSTRACT}

ORCID IDs of the authors: F.B. 0000-0003-1854-7437; M.H. $0000-0002-5468-5338 ;$ T.C. 0000-0002-2096-6975; M.Y. 0000-0002-5841-7015; A.A. 0000-0003-2378-4197; A.S. 0000-0002-7500-8651; G.B. 0000-0003-1702-0772; M.H.K. 0000-0002-1006-2024; G.K. 0000-0003-1933-9824.

\section{Cite this paper as:} Başak F, Hasbahçeci M, Canbak T, Yücel M, Acar A, Şişik A, Baş G, Karabulut MH, Kır G. An incidental giant preperitoneal fibrolipoma diagnosed during laparoscopic cholecystectomy. Turk J Surg 2018; 34: 143-145.

'Department of General Surgery, Ümraniye Training and Research Hospital, İstanbul, Turkey ${ }^{2}$ Department of General Surgery, Bezmialem Vakıf University School of Medicine, İstanbul, Turkey

${ }^{3}$ Department of Pathology, Ümraniye Training and Research Hospital, İstanbul, Turkey

\section{Corresponding Author} Fatih Başak e-mail:fatihbasak@gmail.com

Received: 12.05 .2015 Accepted: 04.08.2015 Available Online Date: 03.01.2018

\section{oCopyright 2018} by Turkish Surgical Association

Available online at www.turkjsurg.com
Preperitoneal lipomas are rare in clinical practice. Here we report an unexpected diagnosis of a giant preperitoneal fibrolipoma detected intraoperatively during laparoscopic cholecystectomy in a 56-year-old woman. The mass was excised and a histopathological examination confirmed fibrolipoma. No recurrence was found on follow-up. In the literature, there have been many cases with unexpected diagnoses during laparoscopy. Here, we present an incidental giant preperitoneal fibrolipoma, which was overlooked by ultrasound and physical examination, but was detected during laparoscopic cholecystectomy.

Keywords: Giant lipoma, preperitoneum, diagnostic errors, laparoscopy

\section{INTRODUCTION}

Lipomas as the most common form of soft tissue tumors are benign lesions composed of adipose tissue. Although these tumors are frequently observed elsewhere on the body, they are rare in thoracic and abdominal cavity (i.e., small and large bowel) and in preperitoneal area (1-4). Although many lipomas are $<1 \mathrm{~cm}$ in diameter, they can grow up to $>6 \mathrm{~cm}$ in diameter. Masses with massive size can cause pressure on adjacent anatomical structures and result in symptoms. Some sources claim that malignant transformation may occur, whether others say that this has yet to be convincingly documented $(1,2)$. Lipomas are classified into various subtypes according to histopathological features, including fibrolipoma, myxolipoma, chondroid lipoma, and myolipoma. The literature contains case reports about preperitoneal lipomas and preperitoneal lipoleiomyoma. Fibrolipomas are known to occur at many various locations such as the esophagus, nerves, oral cavity, spermatic cord, and retroperitoneum (5). Preperitoneal fibrolipoma are exceptionally rare; to the best of our knowledge, this is the first case reported.

In this study, we present a case of a giant preperitoneal fibrolipoma that was missed with routine imaging modalities and physical examination and was incidentally diagnosed during laparoscopic cholecystectomy.

\section{CASE PRESENTATION}

A 56-year-old woman was admitted with abdominal discomfort and pain. Medical evaluation included physical examination, blood tests, and ultrasound focused on the hepatobiliary system. All were normal except a sonographic diagnosis of cholelithiasis. The patient's body mass index was $31 \mathrm{~kg} / \mathrm{m}^{2}$. The patient underwent surgery for cholelithiasis. Laparoscopy was performed via the open entrance method at midline below the umbilicus. A $360^{\circ}$ exploration of the abdomen revealed a giant mass with a diameter of $16 \mathrm{~cm}$. The mass was found protruding into the abdomen near the umbilical trocar entry. It was regarded as a lobulated preperitoneal lipoma due to its macroscopic appearance (Figure 1). First, the mass was carefully excised via open surgery (midline incision under the umbilicus) so as to not shatter it. Midline incision was closed except the trocar area. Then, additional trocars were placed, and standard laparoscopic cholecystectomy was performed uneventfully.

Gross examination of the specimen revealed a firm, rubbery mass, which was encapsulated by a smooth surface, weighed $750 \mathrm{~g}$, and measured $16 \mathrm{~cm}$ in diameter. On pathological examination, all cellular components of the tumor including adipocytes, fibroblasts, and vascular elements appeared benign. There were no signs of cellular atypia, increased mitotic activity, or necrosis. Immunohistochemical staining was positive for S-100 at mature adipocytes and negative for desmin and smooth muscle actin in the fibromatous areas (Figure 2). The patient was discharged at first postoperative day uneventfully. No recurrence or relapse occurred at the 6-month follow-up. 

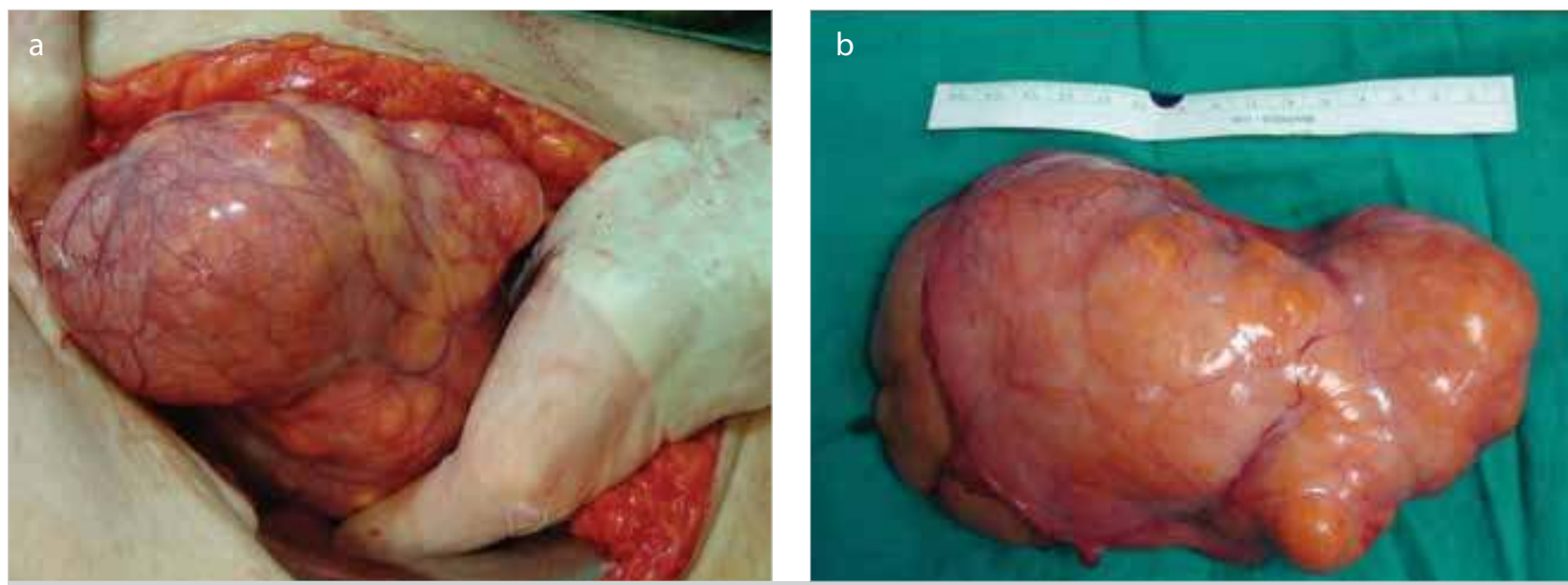

Figure 1. a, b. A surgical view; (a) Intraoperative view of mass, (b) Excised specimen
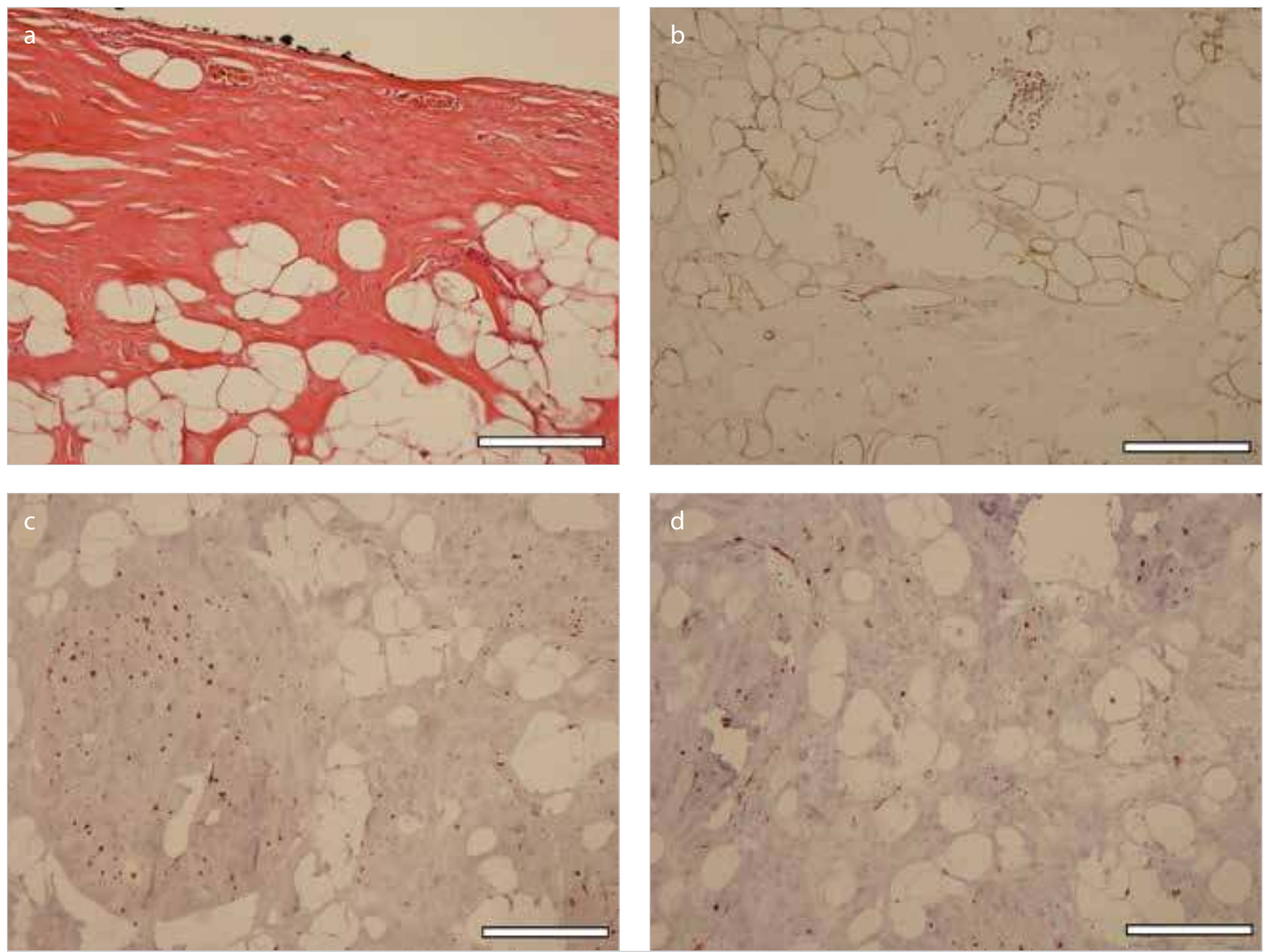

Figure 2. a-d. Microscopic imaging of specimen with different methods; (a) H/E $\times 200$, (b) S-100 $\times 200$, (c) Desmin $\times 200$, (d) SMA $\times 200$, Scale bar: $100 \mu \mathrm{m}$

\section{DISCUSSION}

Lipomas are benign adipose tissue tumors. The etiology is not clear and is known to be both sporadic and inherited. Fibrolipomas are one of the less common histological subtypes of lipoma and have significant fibrous components mixed with fat lobules $(1,6)$. Although a possible relationship between obesity and lipoma occurrence is suspected, it has not yet been proven (7).
Fibrolipomas are benign lesions. In the literature, recurrences and malignant transformations have been reported. There is a controversy regarding whether giant lipomas (i.e., in particular those $>10 \mathrm{~cm}$ or weighing $>1000 \mathrm{~g}$ ) are typical lipomas or liposarcomas. Rapidly growing lipomas of $>10 \mathrm{~cm}$ in size should be considered as possible liposarcomas. Depending on their locations, they may cause intestinal obstruction (5). In the present case, although the mass was $16 \mathrm{~cm}$ in diameter, 
intestinal obstruction at admission was not seen due to its preperitoneal localization.

Management and prognosis of fibrolipomas do not differ from other forms of lipomas. The choice of treatment is complete surgical excision. Although the surgery is curative in most cases, postoperative follow-up is also recommended $(1,5)$. Besides the absence of sarcomatous malignant transformation at histology and prominent lipomatous lesions over the body, the present case was admitted to a follow-up program due to the diameter of the mass. However, life-long follow-up may not be considered for patients with similar findings due to cost-effectiveness.

In the literature, various cases of incidental findings during laparoscopy have been reported. These intra-abdominal lesions include liver metastasis, gastric cancer, stromal tumor of the small bowel, pancreatic cancer, and mucocele of the appendix (8). In the present case, we detected a giant mass located near the umbilicus via a $360^{\circ}$ abdominal exploration during laparoscopic cholecystectomy.

Although complete abdominal exploration during laparoscopic cholecystectomy was questioned in the literature, it is generally recommended to perform this exploration to lower the chance of missed malignancies after laparoscopy (9-11). Missed diagnosis in ultrasound is another challenging problem (12). Furthermore, the use of hepatobiliary ultrasound for the diagnosis of cholelithiasis in an obese patient might cause such problems as in this case. Although additional imaging has not been regarded as the routine practice before laparoscopic cholecystectomy for all cholelithiasis cases, discordance between symptomatology and physical examination should warn physicians to perform detailed radiological examination.

\section{CONCLUSION}

$360^{\circ}$ surgical exploration for major pathologies can be accepted as the routine practice during laparoscopy. Preperitoneal fibrolipoma is a rare condition and can be found incidentally. Complete surgical excision is the choice of treatment. Because of the risk of recurrences and malignant transformations, careful postoperative follow-up is recommended, especially for giant lipomas.

Informed Consent: Written informed consent was obtained from patient who participated in this study.
Peer-review: Externally peer-reviewed.

Author Contributions: Concept - F.B., M.H.; Design - F.B., M.H.; Supervision - F.B., M.H., T.C., M.Y., Data Collection and/or Processing - F.B., M.H., T.C., M.Y., A.A., A.Ş., G.B., M.H.K., G.K.; Analysis and/or Interpretation F.B., M.H., T.C., M.Y., A.A., A.Ş., G.B., M.H.K., G.K.; Literature Search - F.B., M.H., T.C., M.Y., A.A., A.Ş., G.B., M.H.K., G.K.; Writing Manuscript - F.B., M.H., T.C., M.Y.; Critical Reviews - A.Ş., G.B., M.H.K., G.K.

Conflict of Interest: The authors have no conflicts of interest to declare.

Financial Disclosure: The authors declared that this study has received no financial support.

\section{REFERENCES}

1. James WD, Berger TG, Elston DM. Dermal and Subcutaneous Tumors, Andrews' diseases of the skin: Clinical dermatology. James WD, Berger TG, Elston DM (Eds). 11th ed. Elsevier, 2011; pp.574619.

2. Prasad S, Ramachandra L, Agarwal S, Sharma D. Successful management of pleural lipoma by video-assisted thoracoscopic surgery. J Minim Access Surg 2012; 8: 19-20. [CrossRef]

3. Yaman I, Derici H, Paksoy S. Symptomatic duodenal lipoma with endoscopic snare polypectomy. Turk J Surg 2014; 30: 103-105. [CrossRef]

4. Sengul N, Dinler K, Boran C, Kalfaoglu ME, Erkol H. Lipoma causing a colo-colic intussusception and mimicking carcinoma. Turk J Surg 2006; 22: 146-149.

5. Chander B, Krishna M, Thakur S, Mahajan N, Vij A, Diwakaran J. Extremely rare giant retroperitoneal fibrolipoma: a case report. J Cancer Res Ther 2012; 8: 314-316. [CrossRef]

6. Mohammad AM, Yakubu AA. Giant Retroperitoneal Lipoma in an Infant. J Surg Tech Case Rep 2010; 2: 33-34. [CrossRef]

7. Bray GA. Medical consequences of obesity. J Clin Endocrinol Metab 2004; 89: 2583-2589. [CrossRef]

8. Hsu TC. Intra-abdominal lesions could be missed by inadequate laparoscopy. Am Surg 2008; 74: 824-826.

9. Rickman A, Kistner RL, Schlinkert RT. Complete abdominal exploration is unnecessary during the treatment of cholelithiasis. J Laparoendosc Surg 1993; 3: 205-208. [CrossRef]

10. O'Hanlon DM, Kerin MJ, O'Donoghue JM, Doyle JP, Flynn JR. Laparoscopic cholecystectomy: potential for missed pathology. Ann R Coll Surg Engl 1994; 76: 315-316.

11. Atabek U, Spence RK, Manigat Y, Barse F, Leese KH, Davies R, et al. Documentation of abdominal exploration during laparoscopic cholecystectomy. Surg Endosc 1995; 9: 22-24. [CrossRef]

12. Whang JS, Baker SR, Patel R, Luk L, Castro A 3rd. The causes of medical malpractice suits against radiologists in the United States. Radiology 2013; 266: 548-554. [CrossRef] 